\title{
Synchronous Buck Converter for Improved Maximum Power Extraction on Small Stand- Alone Wind Power System using Modified perturb and observe (P\&O)
}

\author{
Irwan Mahmudi ${ }^{1 *}$, Ratih Mar'atus Sholihah. ${ }^{1}$, Baso Muchlis ${ }^{1}$, Sundun Sada Maripi ${ }^{1}$, and \\ Lukman $^{1}$
}

${ }^{1}$ Department of Electrical Engineering, Tadulako University, Palu

\begin{abstract}
To increase the extraction power of a wind power system, the system must work at peak power. This paper presents maximum power extraction and control systems using a modified perturb and observe algorithm (MP\&O) to achieve high efficiency maximum power extraction of wind turbines that connected to permanent magnet synchronous generators (PMSG). To get maximum power from PMSG, MP\&O controls the duty cycle of synchronous buck based on the output power of the 12 pulses rectifier. The simulation results show that MP\&O can work optimally at every change of wind speed. MP\&O was also tested and compared with simple $\mathrm{P} \& \mathrm{O}$ in terms of ripples under stable conditions, response speed and ability to obtain maximum energy output. The average efficiency and convergence time achieved by MP\&O are $99.24 \%$ and 0.71 s.
\end{abstract}

\section{Introduction}

Today, electrical energy needs for humans has a very important role. therefore, electrical energy needs are increasing. By the increasing needs for electrical energy, an increase in energy generation is needed to sufficient the increasing demand. At the same time, it is necessary to use clean and renewable energy to minimize the impact of environmental damage [1] [2] [10]. Wind energy is a renewable energy source that has achieved significant technological advances in security, friendliness and efficiency. International organizations such as The Global Wind Energy Council (GWEC) report that more than 90 countries have built 54 GW of wind energy in 2017 [3].

In the converting application of mechanical energy into electrical energy in wind turbine systems, there are two types of generator structures that have been widely used, the first is known as doubly fed induction generators (DFIG) and the second permanent magnet synchronous generator (PMSG). Although both of these structures have features to increase efficiency, reduce aerodynamic loads, and ease regulation of active and reactive power.

\footnotetext{
* Corresponding author: irwan.mahmudi@untad.ac.id
} 
However, PMSG is more reliable than DFIG in self exited and gearbox [4]. Therefore, PMSG was used in this study.

In utilizing PMSG to supply loads, it will cause several problems, namely the instability condition of voltage, output power, and frequency due to wind speeds that change with time and cannot be predicted in magnitude. For this reason, the PMSG needs a control system to maintain instability and control the PMSG's performance while operating. The control of the wind turbine system can be done with torque control, speed control and power control.

Torque control is used to maintain the wind turbine torque caused by variation of turbine rotation. Speed control is used to control the forward motion (pitch) of the wind turbine when the wind speed exceeds the nominal speed. Meanwhile, power control is aimed at making the wind turbine produce maximum output power. Controlling PMSG to achieve maximum power point (MPP) can be done by varying the load using an electronic interface circuit. The interface can be carried out by a back-to-back converter or a full rectifier diode connected with a dc-dc converter [5]. According to using a full rectifier connected to a dc-dc converter is a simple control strategy, cheaper and more reliable for small scale wind turbines. Therefore, dc-dc buck converter is used in this study.

To determine the optimal operating point of the wind turbine, MPPT algorithm is needed to controlling the torque, speed and power of the wind turbine. MPPT is expected to be able to detects peak power values quickly and precisely so that the power released by PMSG can be maximized. Algorithm approaches that have been used such as tip speed ratio (TSR), optimum torque control (OTC) [9], power signal feedback (PSF), fuzzy logic, fuzzy-PI and perturbation and observation (P\&O) [1] [6] [7].

The purpose of this research is to analyze MPPT control system with PMSG generator. According to the reviewed literature, controlling MPPT is the most important part of wind turbine control. It shows trends in the use of MPPT control with an expert control system (ESC) for wind turbines. Control methods such as OTC, TSR, PSF, Fuzzy and PI need detailed specifications from PMSG and wind turbines. So, it is not flexible for different PMSGs. In this paper, we present a summary of the developed control algorithm for ESC.

$\mathrm{P} \& \mathrm{O}$ is a simple and easy-to-implement algorithm because no wind speed parameter information is needed. However, determining the step size is very important to get the optimal tracking speed and fast response. Large step size will accelerate the tracking speed but with the risk of oscillation in stable conditions [10]. Conversely, small step size will improve optimal tracking accuracy but with slow downtime. In this study, simple P\&O was modified by adjusting the optimal tracking step size, thus accelerating tracking and being able to reduce oscillation in a stable time.

\section{Procedures}

\subsection{Wind Turbine System}

Figure 1 illustrates the proposed wind energy conversion (WECS). PMSG is directly connected to the horizontal axis of the three-blade wind turbine. PMSG output terminals are connected with a 12-pulse diode rectifier and synchronous buck converter to increases PMSG optimal power. The MPPT method is used to determine the optimal duty cycle of the synchronous buck converter based on the output power of rectifier. The proposed MPPT method is a modified $\mathrm{P} \& \mathrm{O}$. 


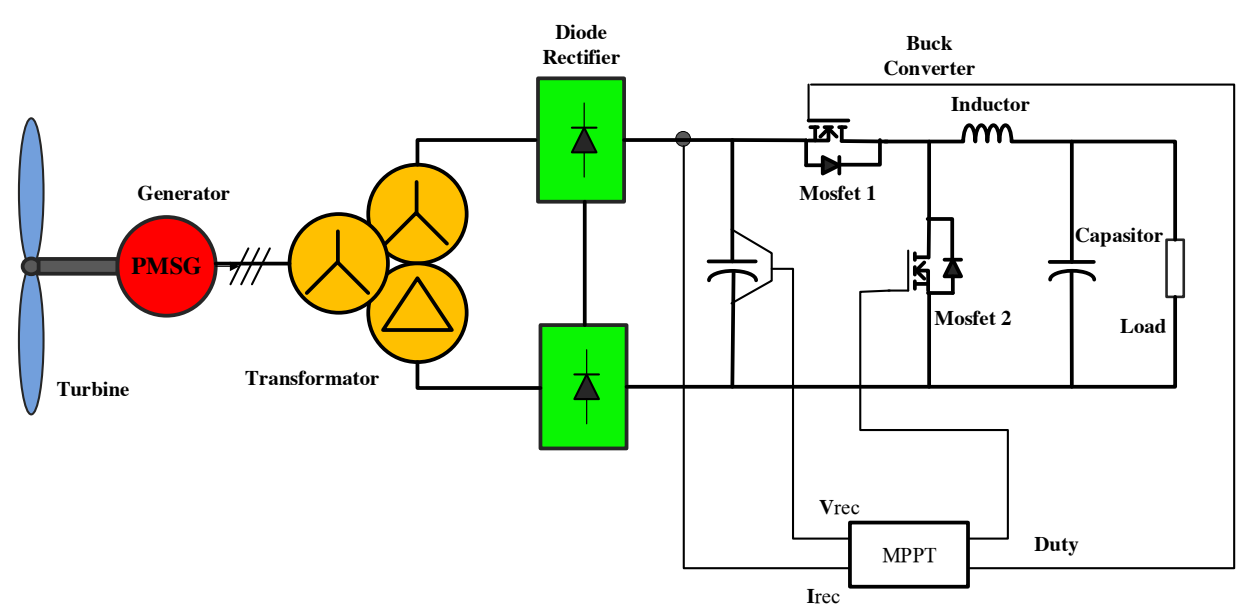

Fig. 1. System Diagram Blocks

Wind turbine is used to converts of wind energy into mechanical energy. Wind energy (Pwind) is the result of half the density of air $(\rho)$ with a cross-sectional area of wind turbine (A) and triple height of the wind speed (V3). The energy drives the wind turbine rotor that is connected to the PMSG generator to produce electrical energy. The maximum output power of a wind turbine is limited by the power coefficient $(\mathrm{CP})$. The power coefficient is a function of the tip speed ratio $(\lambda)$. Mechanical power (PM) produced by wind turbines can be formulated as follows:

$$
\begin{aligned}
& P_{m}=\frac{1}{2} C \rho \pi R^{2} v_{w}^{3} \\
& T_{m}=\frac{1}{2} C_{T} \rho \pi R^{3} v_{w}^{2}
\end{aligned}
$$

With:

$$
\begin{aligned}
& \mathrm{Pm}=\text { mechanical turbine power (watts) } \\
& C_{T}=\text { torque coefficient of turbine } \\
& \rho \quad=\text { air density }(\mathrm{kg} / \mathrm{m} 3) \\
& \pi R^{2}=\text { area catching the wind }(\mathrm{m} 2) \\
& v_{w}=\text { wind speed }(\mathrm{m} / \mathrm{s})
\end{aligned}
$$

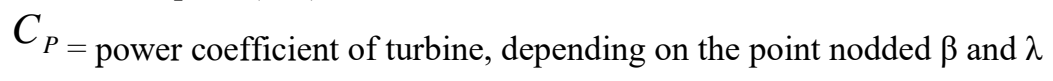

Value tip speed rasio (TSR) is given by:

$$
\lambda=\frac{R \omega_{m}}{v_{m}}
$$

And, $\mathrm{CP}$ value is a function from $(\beta, \lambda)$ expressed by:

$$
C_{T}=\frac{C_{P}}{\lambda}
$$




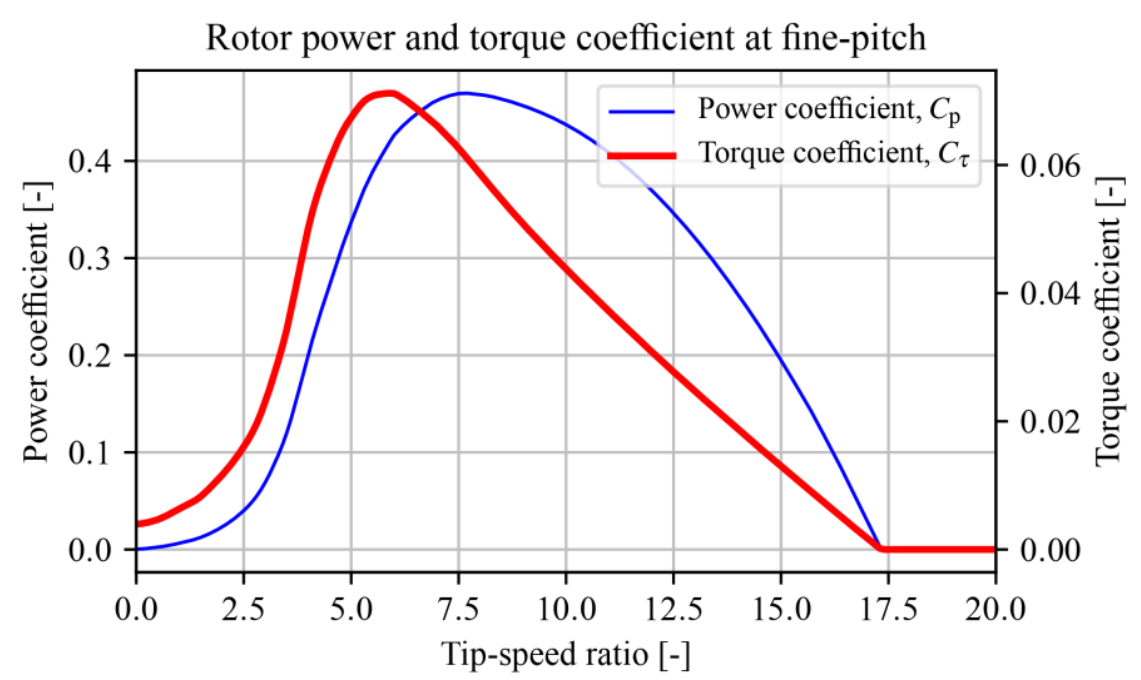

Fig. 2. Power conversion coefficient curve

\subsection{PMSG Model}

Generator is a tool of converting mechanical energy into electrical energy. The generator converts the torque $T m$ and the rotational speed of the $w m$ rotor thatis received from the blade into the value of $\mathrm{V}$ voltage and current $\mathrm{I}$. The output from this generator is 3 phase AC electricity. In this research uses PMSG generator type because it allows a direct drive system without using a gearbox and has a selfexcited. This solution is very usefull because it causes low maintenance constraints. But the generator design is completely separated from the voltage supply from the power converter (AC / DC / AC) connected to the stator. Dynamic equation based on the reference dq as follows:

$$
\begin{aligned}
& V_{d}=R_{s} i_{d}-\omega_{e} \psi_{q}+\frac{d \psi_{d}}{d t} \\
& V_{Q}=R_{s} i_{q}-\omega_{e} \psi_{d}+\frac{d \psi_{q}}{d t}
\end{aligned}
$$

Where id, iq, Vd, Vq is the current and voltage of the reference dq. Lq and Ld is the rotor and stator inductor, Rs is the stator resistance and $\omega_{e}$ is the speed of the rotor based on the electrical frequency of the stator.

$$
\begin{gathered}
\psi_{d}=L_{d} i_{d}+\psi_{f} \\
\psi_{q}=L_{q} i_{q}+\psi_{q}
\end{gathered}
$$

$\psi_{f}$ is the magnetic rotor flux and $\mathrm{P}$ is the number of poles of the generator. By using the iq equation, the electric torque can be calculated with the equation below:

$$
T_{e}=\frac{3}{2} P \psi_{f} i_{q}
$$

\subsection{Synchronous Buck Converter}

Buck converter is a DC-DC converter that functions to reduce voltage by regulating duty cycle switching. Designing a buck converter for MPPT wind turbines requires the desired 
parameters. Following is the equation in determining synchronous buck converter parameters:

$$
\begin{gathered}
V=\frac{V_{o}}{V_{\text {in }}} \\
L=\frac{V_{\text {in }}(1-D) D}{\Delta I L x f s} \\
C=\left(D \cdot V_{\text {in }}+\Delta V\right) \frac{(1-D)}{f s \cdot R \cdot \Delta V}
\end{gathered}
$$

With:

$$
\begin{array}{ll}
\mathrm{D} & =\text { Duty cycle } \\
V_{o} & =\text { Output Voltage }(\mathrm{Vdc}) \\
V_{\text {in }} & =\text { Input Voltage }(\mathrm{Vdc}) \\
\mathrm{L} & =\text { Inductor }(\mathrm{mH}) \\
\mathrm{C} & =\text { Capacitor }(\mu \mathrm{F}) \\
\Delta \mathrm{IL} & =\text { Ripple Inductor }(\mathrm{A}) \\
\Delta \mathrm{V} & =\text { Ripple Voltage }(\mathrm{Vdc}) \\
\mathrm{Fs} & =\text { Frequency Switching }(\mathrm{Hz}) \\
\mathrm{R} & =\text { Resistance }(\Omega)
\end{array}
$$

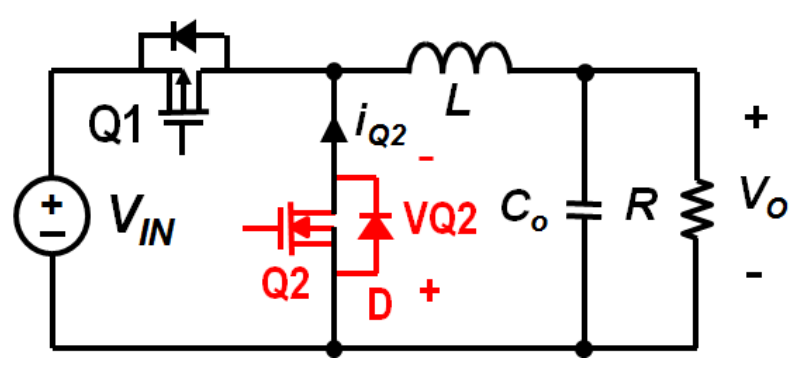

Fig. 3. Synchrounus Buck Convereter

\subsection{P\&O Modified Algorithm}

The perturb and observe $(\mathrm{P} \& \mathrm{O})$ method can be used to determine the optimum point. By using the $\mathrm{P} \& \mathrm{O}$ method, the maximum power value can be obtained without having to know the characteristics of the wind turbine system [12]. The maximum power value is obtained by regulating the amount of DC voltage on the synchronous buck converter. With a large change in dc voltage on the converter, the power value will also change. This method regulates and observes each of these changes. Changing are determined at a certain step-size $\mathrm{D}(\mathrm{t}+1)$ and time. The value of the electric power that generated is compared to the previous electric power. This determines the next variable $D(t+1)$. If the value of the power produced increases then the variable $D(t+1)$ will be of fixed value, if the value of the power produced decreases, the variable $\mathrm{D}(\mathrm{t}+1)$ will changes to be lower to reduce oscillation when the peak stable state is maximum. The working principle of this method can be seen based on Figure 5.

$\mathrm{P}$ is the power generated by the PMSG generator and directed by a 12-pulse rectifier, and $\mathrm{D}$ is the duty cycle to regulate the synchronous buck converter voltage output. $\mathrm{X}$ is the step duty cycle value. Whereas $\mathrm{C}$ is the value multiplied by the value of $\mathrm{X}$, so $\mathrm{C}$ will decrease in 
each rare cycle of $\mathrm{P} \& \mathrm{O}$. With this modification, the resulting ripple will be reduced and the response speed is maintained properly.

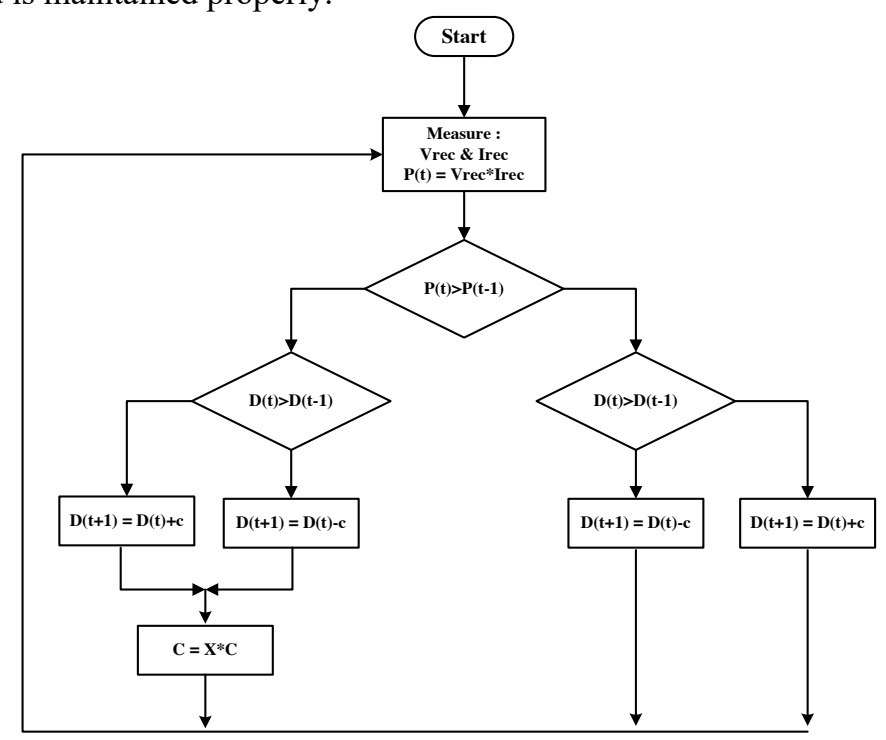

Fig. 4. $P \& O$ Modification Flowchart

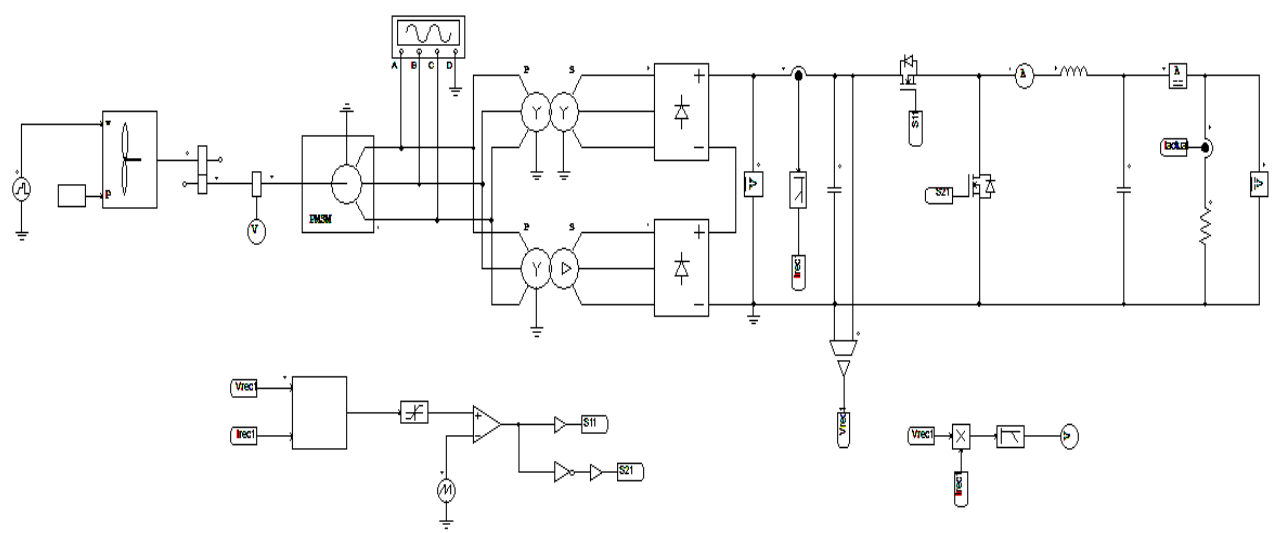

Fig. 5. Schematic for the designed WECS with the proposed MPPT

\section{Result and Discussion}

Coefficients of Power (Cp), Duty Cycle (D), Output Current (A) and Power (P) are used to measure the performance of each method, these parameters are shown in table 1 . The selected wind speed parameters are $7-10 \mathrm{~m} / \mathrm{s}$. Simple P\&O parameter for track constant c $(0.05)$. The parameters of the Modified P\&O track constant $\mathrm{c}(0.05)$ and the multiplier factor $\mathrm{x}(0.9)$. Figures 7 to 11 show the performance curve of each method under variating conditions of wind speed. Table 2 shows the tracking results of each method in each changing of wind speed that shows the tracking response, duty cycle, current, power and efficiency.

The two methods compared can work optimally under conditions of variations in wind speed, but when the results are compared the modification of $\mathrm{P} \& \mathrm{O}$ is able to produce 
maximum power and oscillation better than simple $\mathrm{P} \& \mathrm{O}$. But simple $\mathrm{P} \& \mathrm{O}$ has a tracking response faster than $\mathrm{P} \& \mathrm{O}$ modification.

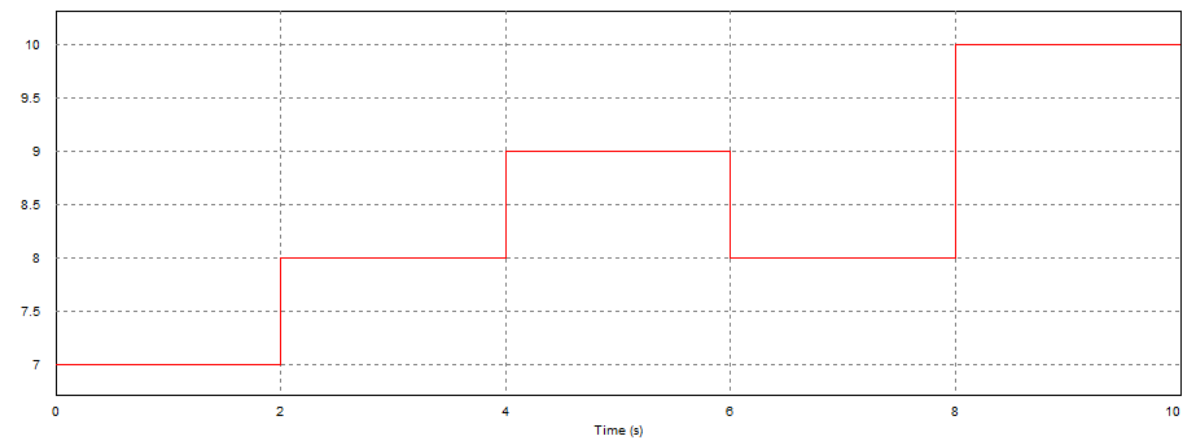

Fig. 6. Wind Velocity Variations

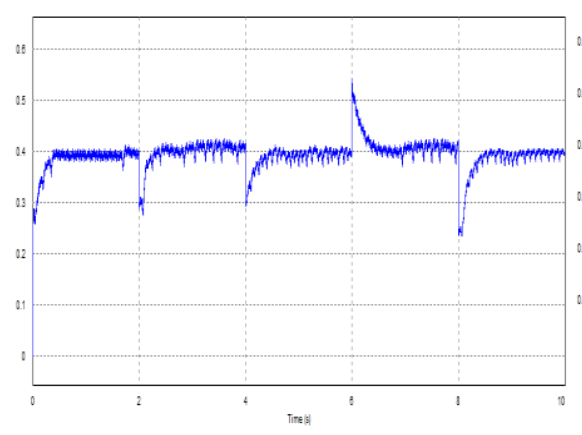

(a)

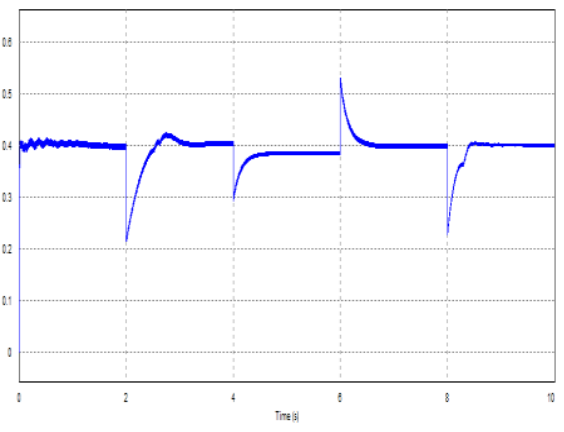

(b)

Fig. 7. CP Variations(a). P\&OStandart (b). P\&O Modified

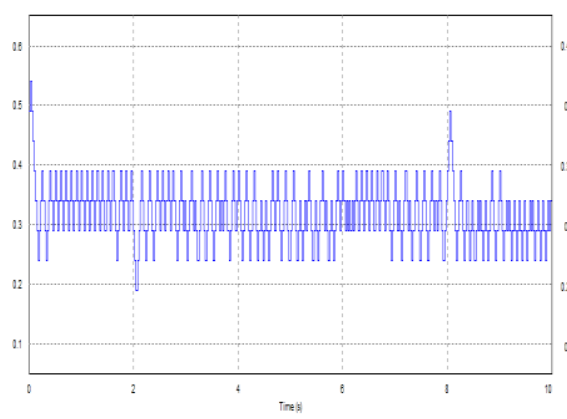

(a).

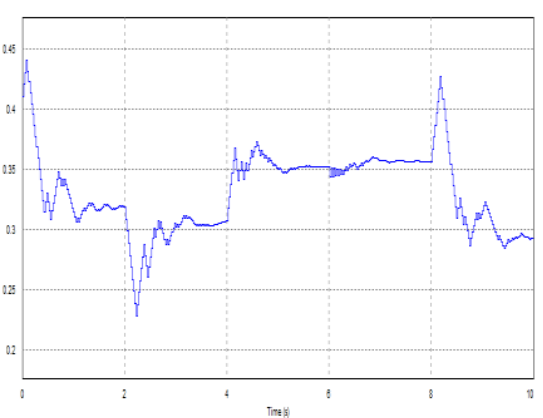

(b).

Fig. 8. Duty Cycle Variations(a). P\&O Standart (b). P\&O Modified 


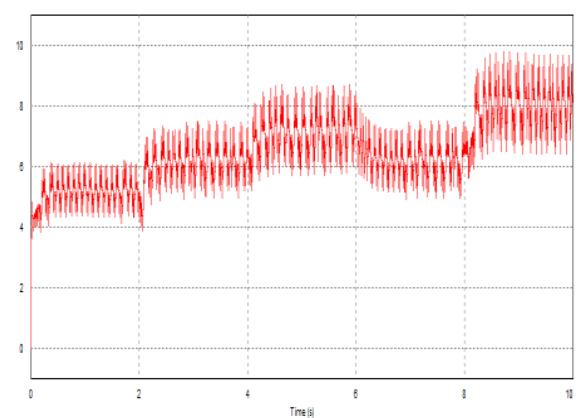

(a).

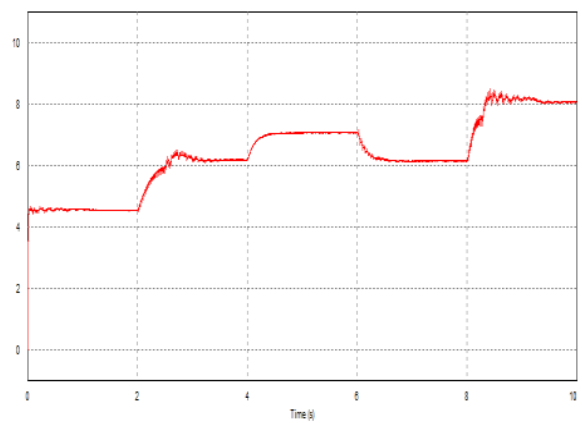

(b).

Fig. 9. Current Output(a). P\&O Standart (b). P\&O Modified

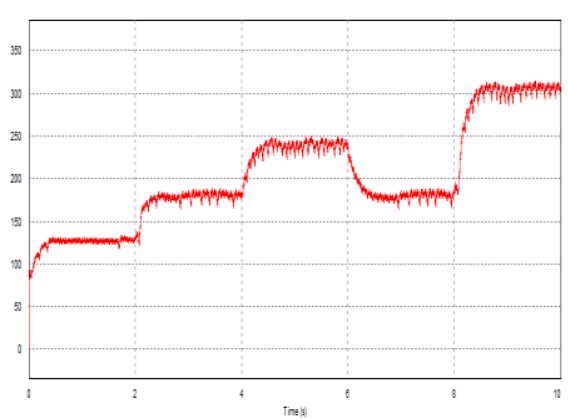

(a)

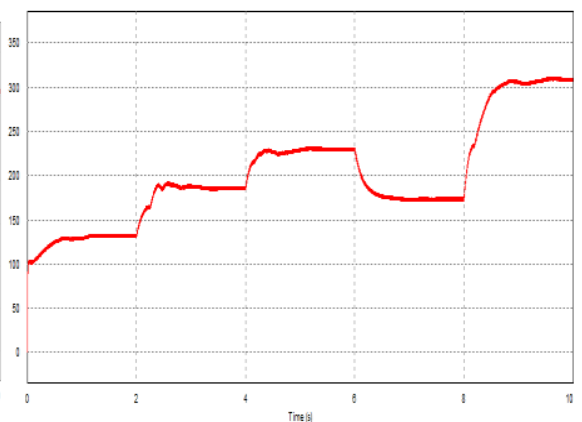

(b)

Fig. 10. Current Output (a). P\&O Standard (b). P\&O Modified

Table 1. Simulation parameters

\begin{tabular}{|c|c|}
\hline Parameters & Value \\
\hline Nominal Out Power of wind turbine & $500 \mathrm{~W}$ \\
\hline Base Wind Speed & $9 \mathrm{~m} / \mathrm{s}$ \\
\hline Momen of Inertia of Wind Turbine & $1 \mathrm{Kg} . \mathrm{m} 2$ \\
\hline Cp maximum & 0,4 \\
\hline TSR & 7.8 \\
\hline Rs (stator resistance) & $5.019 \mathrm{ohm}$ \\
\hline Ld & $0.0082 \mathrm{H}$ \\
\hline Lq & $0.0082 \mathrm{H}$ \\
\hline Number of Pole Pairs & 18 \\
\hline Momen of Inertia of PMSG & $0.01197 \mathrm{Kg} . \mathrm{m} 2$ \\
\hline Vs(min) & $70 \mathrm{Volt}$ \\
\hline Vs(max) & $110 \mathrm{Volt}$ \\
\hline Vo & $48 \mathrm{~V}$ \\
\hline Io & $10,4 \mathrm{~A}$ \\
\hline Switching Frequency (fs) & $100 \mathrm{KHz}$ \\
\hline D & 0.488 \\
\hline L & $33 \mathrm{uH}$ \\
\hline C & $3 \mathrm{uF}$ \\
\hline
\end{tabular}


Table 2. Output of $\mathrm{P} \& \mathrm{O}$ Conventional and Modified P\&O

\begin{tabular}{|c|c|c|c|c|c|c|c|c|}
\hline $\begin{array}{l}\text { Wind } \\
\text { Speed } \\
(\mathbf{m} / \mathbf{s})\end{array}$ & $\begin{array}{l}\text { Max } \\
\text { Power } \\
\text { (Watt) }\end{array}$ & $\begin{array}{l}\text { Tracking } \\
\text { Method }\end{array}$ & $\begin{array}{l}\text { Power } \\
\text { Track } \\
\text { (Watt) }\end{array}$ & $\begin{array}{l}\text { Coefficient } \\
\text { Power } \\
\text { (Cp) }\end{array}$ & $\begin{array}{c}\text { I } \\
\text { (A) }\end{array}$ & $\begin{array}{l}\text { Tracking } \\
\text { speed } \\
\text { (S) }\end{array}$ & $\begin{array}{c}\text { Steady } \\
\text { stade } \\
\text { Ripple }\end{array}$ & $\begin{array}{c}\eta \\
(\%)\end{array}$ \\
\hline \multirow{2}{*}{7} & \multirow{2}{*}{130} & $\begin{array}{c}\text { P\&O } \\
\text { Standard }\end{array}$ & 127,19 & 0,39 & 5,2 & 0,454 & Min & 97,83 \\
\hline & & $\begin{array}{c}\text { Modified } \\
\text { P\&O }\end{array}$ & 129,02 & 0,396 & 5,27 & 0,5 & Min & 99,24 \\
\hline \multirow{2}{*}{8} & \multirow{2}{*}{181} & $\begin{array}{c}\mathrm{P} \& \mathrm{O} \\
\text { Standard }\end{array}$ & 180,73 & 0,399 & 6,19 & 0,799 & Min & 99,85 \\
\hline & & $\begin{array}{l}\text { Modified } \\
\text { P\&O }\end{array}$ & 178,38 & 0,394 & 6,1 & 0,56 & Min & 98,55 \\
\hline \multirow{2}{*}{9} & \multirow{2}{*}{244} & $\begin{array}{c}\mathrm{P} \& \mathrm{O} \\
\text { Standard }\end{array}$ & 239,3 & 0,392 & 7,07 & 0,548 & Min & 98,07 \\
\hline & & $\begin{array}{l}\text { Modified } \\
\text { P\&O }\end{array}$ & 242,13 & 0,396 & 7,17 & 0,95 & Min & 99,23 \\
\hline \multirow{2}{*}{10} & \multirow{2}{*}{310} & $\begin{array}{c}\text { P\&O } \\
\text { Standard }\end{array}$ & 303 & 0,398 & 8 & 0,506 & Min & 97,74 \\
\hline & & $\begin{array}{c}\text { Modified } \\
\text { P\&O }\end{array}$ & 309,8 & 0,4 & 8,21 & 0,84 & Min & 99,93 \\
\hline
\end{tabular}

\section{Conclusion}

In this paper, the modification of $\mathrm{P} \& \mathrm{O}$ by adding a multiplier $\mathrm{x}(0.9)$ has been tested through simulation using PSIM 9.3 software. Adding the multiplier (x) to each iteration results in faster convergence and optimum maximum power tracking efficiency in every variation of wind speed. $\mathrm{P} \& \mathrm{O}$ modification better than a simple $\mathrm{P} \& \mathrm{O}$, it is shown that the efficiency reaches $99.24 \%$ and the tracking response is $0.71 \mathrm{~s}$. The next research will be tested with a prototype wind turbine emulator system in the laboratory. To see the real performance of both methods.

\section{References}

1. Ernesto C, Mario T, Juan C, Roberto V, Jose G., Expert Control Systems for Maximum Power Point Tracking in a Wind Turbine with PMSG: State of the Art, MDPI Journal. 9-2469, (2019)

2. Court, V. Energy capture, technological change, and economic growth: An evolutionary perspective. BioPhys. Econ. Resour. Qual. 3, 1-27, (2018)

3. Sawyer, S., Dyrholm, M., Global Wind Report Annual Market Update 2017, GWEC Global Wind Energy Council: Brussels, Belgium, (2018)

4. Slah, H., Mehdi, D., Lassaad, S., Advanced control of a PMSG wind turbine. Int. J. Mod. Nonlinear Theory Appl. 5, 1-10(2016)

5. Abdullah, M.A.; Yatim, A.H.M.; Tan, C.W.; Saidur, R., A review of maximum power point tracking algorithms for wind energy systems, Renew. Sustain. Energy Rev. 16, 3220-3227(2012)

6. Ambika S, Dinesh K., Maximum Power Point Tracking Control for Wind Energy Conversion System Using PID Controller and Fuzzy Logic, International Journal of Advanced Research in Computer and Communication Engineering. Vol.6, issue 10, (2017) 
7. Tiwari, R.; Babu, N.R., Recent developments of control strategies for wind energy conversion system. Renew. Sustain. Energy Rev. 66, 268-285(2016)

8. Ratna I.P, Irwan M, Margo P, Ardyono P, Taufik T, Mauridhi H, Modified Firefly Algorithm for Improved Maximum Power Extraction on Wind Energy Conversion System, International Journal of Renewable Energy Research, Vol.8., No.3, September (2018)

9. Kumar D, Chatterjee K. A review of conventional and advanced MPPT algorithms for wind energy system. Renew. Sustain. Energy Rev. 55, 957-970(2016)

10. Hong CM, Chen $\mathrm{CH}$, Tungm CS. Maximum power point tracking-based control algorithm for PMSG wind generation system without mechanical sensors. Energy Conversion and Management. 69, 58-67(2013)

11. Z. M. Dalala, Z. U. Zahid, W. Yu, Y. Cho, and J. S. Lai, Design and analysis of an MPPT technique for small-scale wind energy conversion systems, IEEE Trans. Energy Convers., vol. 28, no. 3, pp. 756-767, Sep. 2013.Ind. Electron. 2011, 58, 29-36 (2013) 